\title{
Trigger Tool-Based Automated Adverse Event Detection in Electronic Health Records: Systematic Review
}

Sarah N Musy ${ }^{1,2}$, MSc; Dietmar Ausserhofer ${ }^{1,3}, \mathrm{RN}, \mathrm{PhD}$; René Schwendimann ${ }^{1,4}$, RN, PhD; Hans Ulrich Rothen ${ }^{5}$, MD, PhD; Marie-Madlen Jeitziner ${ }^{5}$, RN, PhD; Anne WS Rutjes ${ }^{6,7}$, PhD; Michael Simon ${ }^{1,2}$, RN, PhD

\footnotetext{
${ }^{1}$ Institute of Nursing Science, University of Basel, Basel, Switzerland

${ }^{2}$ Nursing \& Midwifery Research Unit, Inselspital Bern University Hospital, Bern, Switzerland

${ }^{3}$ College for Health Care Professions, Claudiana, Bolzano, Italy

${ }^{4}$ University Hospital Basel, Patient Safety Office, Basel, Switzerland

${ }^{5}$ Department of Intensive Care Medicine, Inselspital Bern University Hospital, Bern, Switzerland

${ }^{6}$ Institute of Social and Preventive Medicine, University of Bern, Bern, Switzerland

${ }^{7}$ Institute of Primary Health Care (BIHAM), University of Bern, Bern, Switzerland
}

\section{Corresponding Author:}

Michael Simon, RN, PhD

Institute of Nursing Science

University of Basel

Bernoullistrasse 28

Basel, 4057

Switzerland

Phone: 41612670912

Email: $\underline{\text { m.simon@unibas.ch }}$

\section{Abstract}

Background: Adverse events in health care entail substantial burdens to health care systems, institutions, and patients. Retrospective trigger tools are often manually applied to detect AEs, although automated approaches using electronic health records may offer real-time adverse event detection, allowing timely corrective interventions.

Objective: The aim of this systematic review was to describe current study methods and challenges regarding the use of automatic trigger tool-based adverse event detection methods in electronic health records. In addition, we aimed to appraise the applied studies' designs and to synthesize estimates of adverse event prevalence and diagnostic test accuracy of automatic detection methods using manual trigger tool as a reference standard.

Methods: PubMed, EMBASE, CINAHL, and the Cochrane Library were queried. We included observational studies, applying trigger tools in acute care settings, and excluded studies using nonhospital and outpatient settings. Eligible articles were divided into diagnostic test accuracy studies and prevalence studies. We derived the study prevalence and estimates for the positive predictive value. We assessed bias risks and applicability concerns using Quality Assessment tool for Diagnostic Accuracy Studies-2 (QUADAS-2) for diagnostic test accuracy studies and an in-house developed tool for prevalence studies.

Results: A total of 11 studies met all criteria: 2 concerned diagnostic test accuracy and 9 prevalence. We judged several studies to be at high bias risks for their automated detection method, definition of outcomes, and type of statistical analyses. Across all the 11 studies, adverse event prevalence ranged from $0 \%$ to $17.9 \%$, with a median of $0.8 \%$. The positive predictive value of all triggers to detect adverse events ranged from $0 \%$ to $100 \%$ across studies, with a median of $40 \%$. Some triggers had wide ranging positive predictive value values: (1) in 6 studies, hypoglycemia had a positive predictive value ranging from $15.8 \%$ to $60 \%$; (2) in 5 studies, naloxone had a positive predictive value ranging from $20 \%$ to $91 \%$; (3) in 4 studies, flumazenil had a positive predictive value ranging from $38.9 \%$ to $83.3 \%$; and (4) in 4 studies, protamine had a positive predictive value ranging from $0 \%$ to $60 \%$. We were unable to determine the adverse event prevalence, positive predictive value, preventability, and severity in $40.4 \%, 10.5 \%, 71.1 \%$, and $68.4 \%$ of the studies, respectively. These studies did not report the overall number of records analyzed, triggers, or adverse events; or the studies did not conduct the analysis.

Conclusions: We observed broad interstudy variation in reported adverse event prevalence and positive predictive value. The lack of sufficiently described methods led to difficulties regarding interpretation. To improve quality, we see the need for a set of recommendations to endorse optimal use of research designs and adequate reporting of future adverse event detection studies. 
(J Med Internet Res 2018;20(5):e198) doi: 10.2196/jmir.9901

\section{KEYWORDS}

patient safety; electronic health records; patient harm; review, systematic

\section{Introduction}

In recent decades, patient safety and quality of care have become a top priority in health care [1-3]. This has led to significant progress, especially regarding innovative use of electronic health records (EHRs). Adverse events (AEs), injuries attributed to medical care that are independent of the patient's underlying condition, nevertheless remain a persistent problem. Apart from the impact on patients, they entail large human and financial burdens at every health care system level [4]. Regarding patient health, AEs' negative consequences include extended hospital stays, higher readmission rates, and higher mortality [5]. Furthermore, AEs may lead to the patients' and their families' loss of trust in their health care professionals (HCPs), their health care system, or both [3]. The estimated prevalence of AEs in hospital inpatients ranges from $3 \%$ to $40 \%$ in acute care settings [2,6-10]. The wide range reflects the challenges involved in detecting and tracking AEs accurately [11].

To improve patient safety, health care organizations need valid and reliable tools to detect and assess AEs [12]. Several tools exist, but their ability to identify AEs is limited, and none of them are broadly accepted [13-15]. Currently, enumerating specific events that endanger patients depends mainly on voluntarily reporting by health care staff $[16,17]$. Systematic evaluations of this approach showed endemic underreporting, with only $2 \%$ to $8 \%$ of all harmful events being identified [18-20]. To depict the situation more robustly, the US Agency for Healthcare Research and Quality (AHRQ) published a set of Patient Safety Indicators (PSIs). Using administrative datasets, PSIs identify potential AEs, but are highly susceptible to variations in coding practice and are limited by many outcomes being easily concealed in the medical record [14]. Therefore, they miss a substantial fraction of AEs (low sensitivity), while producing a substantial fraction of false positive results (low specificity) [13,21].

One promising method is the Global Trigger Tool (GTT), developed by the Institute for Healthcare Improvement (IHI) [22]. Providing a structured method for identifying AEs from patient records $[23,24]$, the GTT is a retrospective record review instrument that uses a list of triggers (or clues), ie, data elements within the health record, to alert reviewers to the potential presence of AEs [22,25]. By focusing on triggers within patient records, the GTT has demonstrated to identify up to ten times as many AEs as other detection methods [13]. Various studies have used the GTT, where some modified the methods, eg, by modifying the set of triggers, or by modifying the review process (eg, one reviewer instead of two for trigger identification). We refer to these modified versions as trigger tool methodology, reserving the term GTT methodology for the IHI's original procedures [24].

The trigger tool was developed as a manual approach, ie, for application by HCPs reviewing patient records. Recently, an increasing interest developed for semi or fully automated AE detection methods using EHRs where lesser time and personnel resources are required for the AE identification [25-28]. Prospective AE detection would supply real-time feedback to HCPs, allowing timely interventions. The development of automated surveillance systems using EHR data has greatly facilitated AEs' identification [28].

Semi or fully automated AEs detection methods show promise to efficiently measure AEs. Nevertheless, evidence need to be summarized based on the current literature to gather information for future development and implementation in a health care organization. As a variety of AEs' detection methods exist, we decided to focus on trigger tool-based AEs detection methods only, allowing comparisons between studies as suggested in a previous systematic review on automated detection of patient harm [29]. As trigger tool methodology has shown higher sensitivity compared with other detection methods, we considered the manual trigger tool as the gold standard. This systematic review aimed to describe current study methods and challenges regarding the use of automatic trigger tool-based AE detection methods in EHRs in acute care settings. In addition, we aimed to appraise the applied studies' designs and to synthesize estimates of $\mathrm{AE}$ prevalence and diagnostic test accuracy (DTA) of automatic detection methods using manual trigger tool as a reference standard.

\section{Methods}

\section{Search Strategy and Study Selection}

This systematic review followed the recommendations of the Cochrane Handbook for Systematic Reviews of Diagnostic Test Accuracy [30], the Cochrane Handbook for Systematic Reviews of Interventions [31], and the Preferred Reporting Items for Systematic Reviews and Meta-Analyses guidelines for the reporting of systematic reviews [32].

Hausner et al's approach was applied to develop a robust search strategy (Multimedia Appendix 1) [33,34]. In PubMed's basic search mode, we entered the following medical subject headings $(\mathrm{MeSH})$ and free-text terms for title and abstract fields: (trigger OR triggers) AND (chart OR charts OR identif* OR record OR records) AND (adverse OR medical errors). The focus of the search was on "trigger" and not on GTT, as we aimed to include studies using variations of the original GTT. The search strategy was transposed to EMBASE, CINAHL, and the Cochrane Library, and terms were mapped to the appropriate keywords (eg, from MeSH to Emtree). Studies published in English, French, German, Italian, or Spanish were considered without restrictions concerning the years of the publication. In addition to searching the bibliographic databases, the team identified additional relevant literature from most common journals publishing in the field of trigger tool: BMJ Quality \& Safety, Journal of Patient Safety, and International Journal for Quality in Health. For pragmatic reasons, the research team decided to 
limit the hand search of the most common journals to the years 2014 to 2017. The search was conducted in November 2015 with updates in April 2016 and July 2017.

We included observational studies that applied a trigger-based tool to detect AEs in EHRs in any acute care setting. We defined the target population of interest as patients hospitalized for at least 48 hours for any reason. The evaluated trigger tool approach (index test) had to involve either semi (ie, one part of the process still manual) or fully automatic identification of AEs [29]. Regarding DTA studies, we opted for a reference standard that produced a relatively low rate of missed AEs alongside an acceptable rate of false positive test results (events flagged as AEs that, upon examination, did not qualify as AEs). As shown by Classen et al (2011), manual trigger-based tools met our target criteria [13]. We excluded studies from nonhospital settings (eg, long-term care), outpatient clinics, or that concerned with nonprimary research (eg, systematic reviews or editorials).

The eligible articles were divided into two sets: (1) an automated trigger tool in comparison with a manual trigger tool method for $\mathrm{AE}$ detection, potentially enabling the evaluation of the trigger tool's DTA (diagnostic test accuracy studies) and (2) application of an automated trigger tool without cross-verification with a manual trigger tool method, enabling us to synthesize the prevalence of AEs and the applied methods. We refer to the latter group as "prevalence studies" throughout this paper.

\section{Data Extraction}

Two main reviewers (SNM and MS) each screened half of the retrieved titles and abstracts for relevance according to the criteria outlined above. The other members of the research team each screened a quarter of the retrieved titles and abstracts, allowing double screening for all citations. Full-text screening was independently assessed by the main two reviewers, where disagreements were resolved by discussion, or by consulting the entire research team, if necessary.

Detailed study information was extracted into tables by SNM and a master student as part of her training. We used standardized piloted extraction sheets to tabulate variables related to design, sample population characteristics, applied trigger tool methodology, type and number of reviewers and triggers, and outcome data expressed as AE prevalence (overall and by AE type). To estimate DTA, we used $2 \times 2$ tables. Whenever possible, we derived the positive predictive value (PPV) of the triggers used. PPV is calculated by dividing the number of true positive triggers related to confirm AEs by the total number of positive triggers.

Unresolved disagreements or uncertainties between SNM and the master student were discussed and resolved in the research team, which included experienced systematic review and GTT methodologists, clinicians, and nurses, each with more than 10 years of experience in their specialty.

\section{Quality Assessment}

We assessed the risk of bias and the concerns regarding applicability of all included studies. With respect to DTA, we assessed the quality of the included studies with the QUADAS-2 instrument, which we adapted for use as recommended by its authors [35]. The tool consists of four domains: (1) patient selection, (2) index test, (3) reference standard, and (4) flow and timing. Each domain contains signaling questions for risk of bias and concerns regarding applicability except the domain flow and timing. Each signaling question has three answer options: yes, no, and unclear. On the basis of the overall rating of the reviewers, an assessment can be made in each domain concerning bias and applicability. For example, one signaling question in the domain patient selection is, "Was a consecutive or random sample of patients enrolled?" All adaptations of the instrument are explained in Multimedia Appendix 2.

For prevalence studies, the research team generated a new tool based on the structure of the QUADAS-2 instrument to assess the risk of bias and concerns regarding applicability. The new tool consisted of six domains: patient selection, reviewer and algorithm selection, automatic detection method, outcomes, and flow and timing. All but outcomes and flow and timing included a section on risk of bias and concern regarding applicability, including signaling questions (Multimedia Appendix 3). The goal of this quality assessment was to verify the quality of the semi or fully automated trigger tool studies by focusing specifically on algorithm development and the basis for choosing each trigger.

Quality assessment process was conducted by one reviewer (SNM), and each research team member received at least one study to compare the results with SNM. Members did each task individually; then all results were discussed jointly by the multidisciplinary research team.

\section{Statistical Analyses}

As we anticipated a paucity of evidence on DTA data, we deemed formal meta-analyses not feasible. For the total number of AEs and each type of AE, we present percentages with $95 \%$ CIs for prevalence, PPV, and rate of false negative test results. For the prevalence studies, we provided percentages for prevalence and PPV with $95 \% \mathrm{CIs}$, for AE overall and per type of trigger.

\section{Results}

\section{Search Strategy and Study Selection}

After removing duplicates, 2658 citations were identified via our search strategy, the core journals, and our personal library. Of these, 11 met all selection criteria: 2 concerned diagnostic test accuracy studies and and 9 prevalence studies. A detailed view of the included studies is provided with a flow diagram in Figure 1. 
Figure 1. Flow diagram of the number of studies found with the search strategy, studies screened, and reasons for exclusions. Eleven studies fulfilled all inclusion and exclusion criteria.

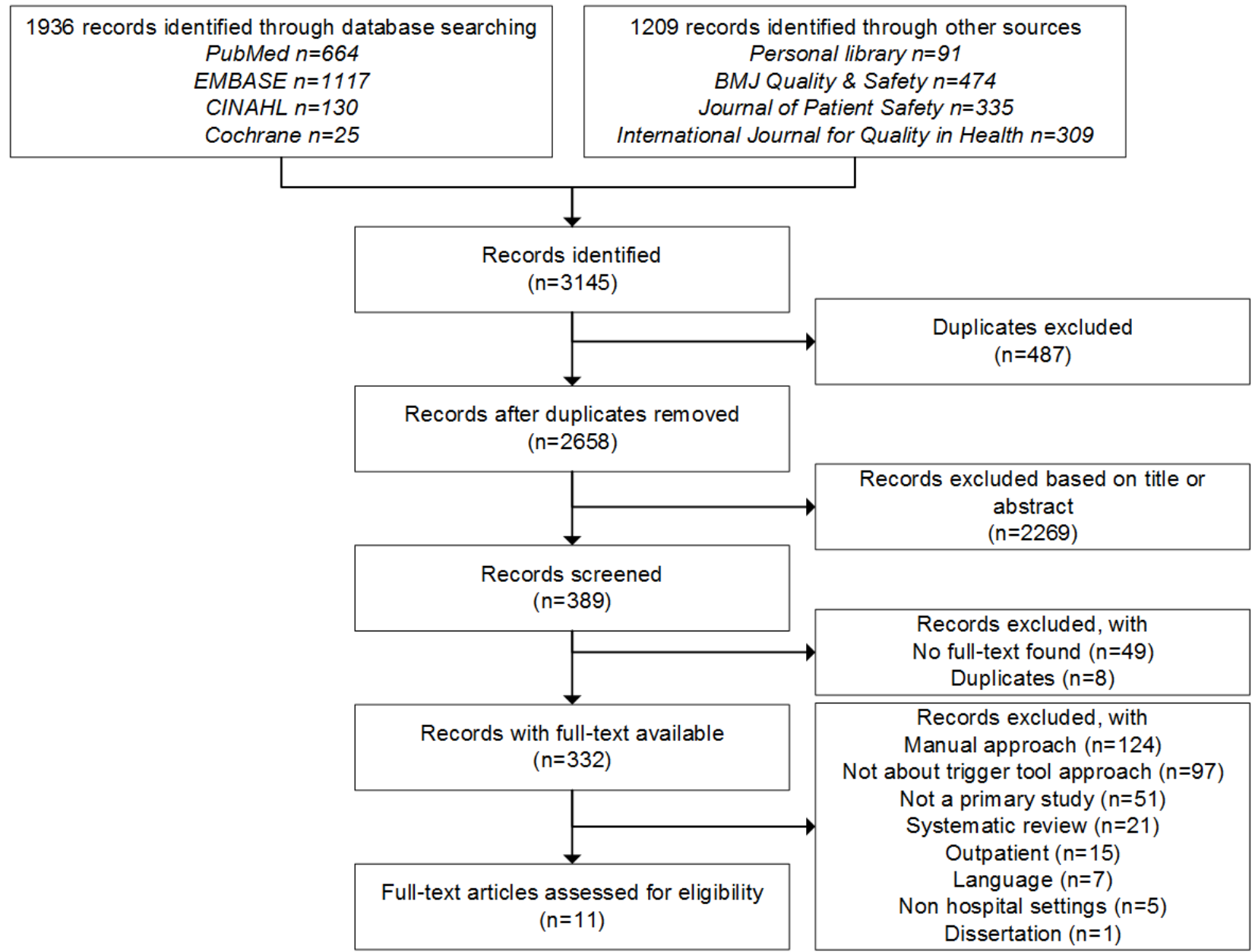

\section{Description of Included Studies}

The studies were published from 2005 to 2016 . Of these, 9 were conducted in the United States [25,36-43], 1 in Denmark [44], and 1 in the United Kingdom [45]. Concerning the study populations, 7 were conducted among pediatric or neonatal patients $[25,36,37,39,40,43,45], 3$ among adults [38,41,42], and 1 , published in abstract form only, provided no population information [44]. Two studies conducted multisite trigger tool research $[25,42]$. The bed capacity of the hospitals involved ranged from 26 to 1000 beds, with a median of 306 . One study provided no information on bed capacity [36]. Further details concerning the design and the characteristics are summarized in Table 1.

One study explicitly followed the IHI guidelines for GTT [42], whereas the other studies used different trigger tool approaches or did not specify whether they followed the IHI guidelines. Concerning methodology, 6 studies addressed only adverse drug events (ADEs) [36,38,39,42,43,45], and only 1 used a fully automatic AE detection approach [44]. Definitions used to define and reference AEs varied [36-38,40-43,45] or were absent $[25,39,44]$. Seven studies used decision or agreement of the reviewer(s) to confirm an $\mathrm{AE}$, without reference to the indexing method used [25,36-40,43]; and 2 studies omitted any explanation of the process $[44,45]$. Five studies did not consider preventability $[38,39,42,44,45]$; in the remainder, definitions varied. Three studies used the definition of a preventable $\mathrm{AE}$ as an "event leading to action deviating from the local standard of care" [37,40,43]; one study used a scale from " 1 - virtually no evidence for management causation" to " 6 - virtually certain evidence for management causation," but without describing the applied cutoff [36]. One study used a 6-point confidence scale from " 1 - virtually no evidence of preventability" to "6-virtually certain evidence of preventability," with a score $\geq 4$ denoting preventability [41]; and one study merely described that preventability was determined by the reviewers' decision [25]. Five studies assessed AEs' severity using the National Coordinating Council for Medication Error Reporting and Prevention (NCC MERP) categories [25,37,39,40,43]; 4 studies did not state their assessment strategies $[38,42,44,45]$; one study categorized them according to four levels of severity (life-threatening, serious, clinically significant, or trivial) [41]; and one used NCC MERP categories together with the Common Terminology Criteria for Adverse Events version 4.03, ranging from mild (grade 1) to death (grade 5) [36]. Information concerning the data source, the triggers, and the reviewer(s) are detailed in Table 2.

Concerning the methodology, 5 studies came from the "Automated Adverse Event Detection Collaborative," which is a consortium to facilitate the use of automated triggers in pediatric hospitals $[25,36,37,39,40,43]$. They all used the same approach, where an EHR-driven surveillance system was used, 
yet not providing detailed information on the software. Every night, trigger reports were automatically generated for laboratory results $[37,40,43]$, medications levels in the blood [36,39], or both [25]. A clinical analyst examined every trigger by reviewing the EHR and interviewing care providers. The potential AEs were reviewed by specialists: pharmacists, physicians, endocrinologists, or anesthesiologists. The clinical analyst met with a multidisciplinary team, the "Automated Adverse Event Detection Steering Committee," monthly to present the results. Two studies used natural language processing (NLP) to extract information from EHRs [41,44]. NLP is defined as a technique extracting information from narrative text and transforming it into structured text $[41,46]$. NLP is able to deal with synonyms, negations, and abbreviations used in narrative text. To build queries, SAS Text Miner tool [44] was used; however, no further details were provided. Structured Query Language [41] was used to identify AEs in the EHRs. The other studies used (1) Electronic trigger-detection messages that were sent automatically to two pharmacist reviewers [42], (2) Computerized trigger alert system that sent an alert to the project manager within 24 hours when conditions defined by the trigger algorithm were detected [38], and (3) electronic algorithms where triggers were identified automatically [45]. No further details concerning the development, the algorithms, or the tools used were given. Description of the methods are explained in Table 3.

Table 1. Design and characteristics of the sample and population of the included studies.

\begin{tabular}{|c|c|c|c|c|}
\hline Study & Population & $\begin{array}{l}\text { Time frame } \\
\text { (months) }\end{array}$ & Sample size & Setting \\
\hline \multicolumn{5}{|l|}{ Diagnostic test accuracy studies } \\
\hline Gerdes and Hardahl, 2013 [44] & Not stated & 26 & 500 & Not stated \\
\hline O’Leary et al, 2013 [41] & $\begin{array}{l}\text { Adults, exclusion of patients admitted } \\
\text { under observation status and cared for } \\
\text { by either of the two medical record } \\
\text { abstractors }\end{array}$ & 12 & 250 & General internal medicine \\
\hline \multicolumn{5}{|l|}{ Prevalence studies } \\
\hline Call et al, 2014 [36] & Children & 48 & 390 & $\begin{array}{l}\text { Oncology } \\
\text { Hematology }\end{array}$ \\
\hline Dickermann et al, 2011 [37] & $\begin{array}{l}\text { Children, exclusion weekend days for } \\
5 \text { months because of resource limita- } \\
\text { tions }\end{array}$ & 12 & 13,526 & $\begin{array}{l}\text { General internal medicine } \\
\text { Surgical care } \\
\text { Emergency department } \\
\text { Intensive care unit (ICU) } \\
\text { Psychiatric unit }\end{array}$ \\
\hline Lim et al, 2016 [42] & Adults & $3 \times 1$ month & Not stated & Not stated \\
\hline Moore et al, 2009 [38] & Adults & 5 & 456 & $\begin{array}{l}\text { General internal medicine } \\
\text { Surgical care } \\
\text { Obstetrics or gynecology }\end{array}$ \\
\hline Muething et al, 2010 [39] & Children & $\begin{array}{l}21 \text { for one trigger } \\
\text { and } 16 \text { for another } \\
\text { one }\end{array}$ & Not stated & Not stated \\
\hline Nwulu et al, 2013 [45] & Not stated & 12 & 54,244 & Not stated \\
\hline Patregnani et al, 2015 [43] & Children & $\begin{array}{l}52 \text { for one trigger; } \\
40 \text { and } 60 \text { for the } \\
\text { others }\end{array}$ & Not stated & $\begin{array}{l}\text { Pediatric ICU } \\
\text { Neonatal ICU } \\
\text { Cardiac ICU } \\
\text { Medical and surgical acute } \\
\text { care areas }\end{array}$ \\
\hline Shea et al, 2013 [40] & Children & 36 & 6,872 & $\begin{array}{l}\text { Pediatric ICU } \\
\text { Cardiac ICU }\end{array}$ \\
\hline Stockwell et al, 2013 [25] & $\begin{array}{l}\text { Children, exclusion of emergency } \\
\text { departments and ambulatory clinics }\end{array}$ & $\begin{array}{l}36 \text { for hospital } 1 \text { and } \\
51 \text { for hospital } 2\end{array}$ & Not stated & $\begin{array}{l}\text { General internal medicine } \\
\text { Surgical care } \\
\text { Psychiatric unit } \\
\text { Neonatal } \\
\text { Cardiac ICU } \\
\text { Pediatric ICU }\end{array}$ \\
\hline
\end{tabular}


Table 2. Data sources, triggers, and reviewers of included studies.

\begin{tabular}{|c|c|c|c|}
\hline Study & Data source & Triggers & Reviewer(s) \\
\hline \multicolumn{4}{|l|}{ Diagnostic test accuracy studies } \\
\hline Gerdes and Hardahl, 2013 [44] & $\begin{array}{l}\text { Unstructured and semistructured narra- } \\
\text { tive texts in EHRs }{ }^{\mathrm{a}}\end{array}$ & $\begin{array}{l}\text { "Models," not defined, identifying the } \\
\text { most common triggers and/or AEs }{ }^{\mathrm{b}}\end{array}$ & Not stated \\
\hline O'Leary et al, 2013 [41] & $\begin{array}{l}\text { Enterprise Data Warehouse: EHRs or } \\
\text { CPOES }^{\mathrm{c}} \text {; hospital and physician billing } \\
\text { systems; incident reporting system; and } \\
\text { admission or discharge or transfer with } \\
\text { nightly updates from activities occur- } \\
\text { ring in the preceding } 24 \mathrm{~h}\end{array}$ & $\begin{array}{l}\text { Locally developed based on screening } \\
\text { criteria from the Harvard Medical } \\
\text { Practice Study and the } \text { IHI }^{\mathrm{d}} \text { GTT }^{\mathrm{e}}\end{array}$ & $\begin{array}{l}\text { Experienced hospitalists and } \\
\text { physician-researcher (prior ex- } \\
\text { perience with the research } \\
\text { method) }\end{array}$ \\
\hline \multicolumn{4}{|l|}{ Prevalence studies } \\
\hline Call et al, 2014 [36] & $\begin{array}{l}\text { EHR: laboratory, pharmacy, electronic } \\
\text { medication administration record, } \\
\text { CPOE, and documentation functions }\end{array}$ & $\begin{array}{l}\text { Wide use in similar population and } \\
\text { high likelihood to detect adverse drug } \\
\text { events }\end{array}$ & Pharmacist and physician \\
\hline Dickermann et al, 2011 [37] & EHRs & Increasing use in hospitals' protocols & $\mathrm{CA}^{\mathrm{f}}$ trained \\
\hline Lim et al, 2016 [42] & $\begin{array}{l}\text { EHR supports all inpatient and ambula- } \\
\text { tory care clinical and documentation } \\
\text { activities }\end{array}$ & $\begin{array}{l}\text { Review of literature and detectable in } \\
\text { EHRs with reasonable } \mathrm{PPV}^{\mathrm{g}}\end{array}$ & $\begin{array}{l}\text { Pharmacists, medication safety } \\
\text { pharmacist, and physician }\end{array}$ \\
\hline Moore et al, 2009 [38] & $\begin{array}{l}\text { CPOE with decision support, EHR, } \\
\text { clinical event monitors }\end{array}$ & $\begin{array}{l}\text { Most common inpatient adverse drug } \\
\text { events }\end{array}$ & Study investigators \\
\hline Muething et al, 2010 [39] & $\begin{array}{l}\text { Clinical information system: computer- } \\
\text { ized clinical order entry, clinical docu- } \\
\text { mentation, electronic medication admin- } \\
\text { istration record, data storage repository, } \\
\text { and advanced clinical decision support }\end{array}$ & AEs steering committee & $\begin{array}{l}\text { Endocrinologist, anesthesiolo- } \\
\text { gist, and frontline staff }\end{array}$ \\
\hline Nwulu et al, 2013 [45] & $\begin{array}{l}\text { Locally developed electronic health } \\
\text { and prescription computer system } \\
\text { (laboratory results and prescribing, ex- } \\
\text { cept some chemotherapy regimens) has } \\
\text { built-in checks to identify potential } \\
\text { prescribing errors (flagged through } \\
\text { warnings and alerts) }\end{array}$ & $\begin{array}{l}\text { Test the usefulness of two medication } \\
\text { module triggers from the GTT pro- } \\
\text { posed by IHI }\end{array}$ & Not stated \\
\hline Patregnani et al, 2015 [43] & EHRs & Clinical evidences & $\begin{array}{l}\mathrm{CA} \text { trained in the } \mathrm{AE} \text { trigger } \\
\text { process }\end{array}$ \\
\hline Shea et al, 2013 [40] & $\begin{array}{l}\text { EHRs and Laboratory Information } \\
\text { System }\end{array}$ & Clinical evidences and risks of deaths & $\begin{array}{l}\mathrm{CA} \text { trained in the } \mathrm{AE} \text { trigger } \\
\text { process }\end{array}$ \\
\hline Stockwell et al, 2013 [25] & EHRs & $\begin{array}{l}\text { Multidisciplinary review process us- } \\
\text { ing several review criteria }\end{array}$ & $\mathrm{CA}$ \\
\hline
\end{tabular}

${ }^{\mathrm{a}}$ EHRs: electronic health records.

${ }^{\mathrm{b}} \mathrm{AE}$ : adverse event.

${ }^{\mathrm{c}} \mathrm{CPOES}$ : computerized provider order entry system.

${ }^{\mathrm{d}}$ IHI: Institute for Healthcare Improvement.

${ }^{\mathrm{e}}$ GTT: Global Trigger Tool.

${ }^{\mathrm{f}} \mathrm{CA}$ : clinical analyst.

${ }^{\mathrm{g}} \mathrm{PPV}$ : positive predictive value. 
Table 3. Overview of the automated trigger tool methodology.

\begin{tabular}{ll}
\hline Study & Description of the method \\
\hline $\begin{array}{l}\text { Diagnostic test accuracy studies } \\
\text { Gerdes and Hardahl, 2013 [44] }\end{array}$ & $\begin{array}{l}\text { (1) Extraction and preparation of all texts from the EHRs }{ }^{\mathrm{a}} \text {; (2) Use of SAS Text Miner and the SAS Enterprise } \\
\text { Content Categorization software to build query models (natural language processing algorithms) }\end{array}$ \\
O'Leary et al, 201 3[41] & $\begin{array}{l}\text { (1) Leveraging of various information systems in the EDW } \\
\text { mimic } \text {; (2) Write Structured Query Language queries to }\end{array}$ \\
& EDW screens; (4) Another reviewer reviews narrative summaries and determines presence of AEs
\end{tabular}

\section{Prevalence studies}

Call et al, 2014 [36]

(1) Software program conducts an extensive search of patient records for any type of order containing specific medications and laboratory values; (2) Information generated into a report with patient-specific information;

(3) Review by two reviewers

Dickermann et al, 2011 [37] (1) Trigger reports automatically generated on a daily basis from the EHR by querying the Sunquest Laboratory Information System for laboratory results; (2) Reviewer examined every trigger by reading the EHRs and interviewing care providers

Lim et al, 2016 [42]

(1) Administration of a trigger drug to a patient automatically sent an electronic trigger-detection message to two reviewers; (2) Trigger-detection messages were evaluated immediately after or during the day by both reviewers (consensus if disagreement); (3) Event reviewed by a medication safety pharmacist and then by a physician for validation.

Moore et al, 2009 [38] $\quad$ (1) The laboratory results and administered medications of each adult hospital patient were continuously monitored by the computerized trigger alert system; (2) If any of the conditions defined was satisfied (trigger algorithm), an alert was triggered, and data were collected by study investigators on the patient for a period of 72 hours after the initial trigger firing to determine whether an adverse drug event had occurred.

Muething et al, 2010 [39] (1) Combination of trigger tool approach with the clinical information system; (2) Every evening, automatic detection of triggers are sent to the project manager (detection of event within $24 \mathrm{~h}$ ); (3) Summary of the incident automatically generated and sent to the appropriate staff on the unit involved

Nwulu et al, 2013 [45] (1) The triggers identified electronically were linked to the electronic prescription records; (2) Two or more positive triggers generated for the same patient, within a 24- or 72-hour interval (trigger-dependent) were treated as one trigger; (3) The paper-based case notes were reviewed to identify any documentation of interest

Patregnani et al, 2015 [43] (1) Generation of a trigger report by querying the Laboratory Information System (2) Reviewer investigated the event by reading the patient's EHRs and interviewing the clinical care team

Shea et al, 2013 [40]

(1) Generation of a trigger report by querying the Laboratory Information System (2) Reviewer investigated the event by reading the patient's EHRs and interviewing the clinical care team

Stockwell et al, 2013 [25]

(1) Automated trigger reports are generated from hospital information systems on a nightly basis; (2) Each trigger report is examined by a reviewer and interviews conducted with care providers.

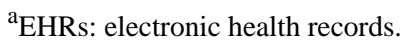

${ }^{\mathrm{b}}$ EDW: Enterprise Data Warehouse.

${ }^{\mathrm{c}}$ AEs: adverse events.

Two studies compared results from automated trigger tool methodology with those obtained via the manual trigger tool method $[41,44]$. Six studies compared results with voluntary incident reports but did not cross-verify their results with those obtained via manually operated trigger-based tools; therefore, we considered these prevalence studies [25,36,37,39,43,45]. The remaining 3 studies did not compare their results with those obtained via any other method $[38,40,42]$.

\section{Quality Assessment}

Figure 2 shows detailed results of the two quality assessments.

\section{Diagnostic Test Accuracy Studies}

In one of the 2 studies, the assessment of all domains was hampered by poor reporting, and we were unable to judge the risk of bias and concerns regarding applicability [44]. In the other, we judged the concern regarding applicability of "patient selection" as low [41]. We judged a high risk of bias in the "flow and timing" domain and low bias risk and applicability concerns for the "index test" and "reference standard" domains [41].

\section{Prevalence Studies}

A total of 9 studies were selected as prevalence studies via our self-developed quality assessment tool (Multimedia Appendix 3 ). For "patient selection," the bias risk was deemed low in seven studies [25,36-38,40,42,43] and applicability concerns were also low in eight of them [25,36-40,42,43]. We had no concerns regarding applicability of the automatic detection methods. As Figure 2 shows, for the other domain, we judged low bias risk and concerns regarding applicability in a minority of studies. In 5 studies, we judged a high risk of bias in the "outcomes" domain, mainly because their AE definitions did not reference those of the IHI or Food and Drug Administration, 
and they lacked clearly stated prevalence outcomes $[37,38,42,43,45]$. We judged high bias risks in 3 studies regarding the "automated detection method" domain $[25,37,45]$. In another, we judged the bias risk as high in the "reviewer or algorithm selection" domain [45] because the triggers were not consistently used or developed, and the reviewer lacked the required profile (eg, experience and training).

\section{Estimates of Diagnostic Test Accuracy, Prevalence, and Reliability}

Estimates of DTA can be found in Table 4, with additional information concerning prevalence, preventability, and false negative rates for AE categories. No information concerning $2 \times 2$ tables were available for all the triggers; thus, the decision was made to use the AE categories.

Figure 2. Risk of bias and concerns regarding applicability assessments for diagnostic test accuracy studies (upper panel) and prevalence studies (lower panel). Judgments are expressed as "low," "high," or "unclear" risk or concern for each of the domains (ie, "patient selection," "index test"). The percentages refer to the percentage of studies meeting the judgment low, high, or unclear risk of bias or concerns regarding applicability in each of the domains. Quality Assessment tool for Diagnostic Accuracy Studies-2 (QUADAS-2) was used for the two diagnostic test accuracy studies and an in-house developed tool was used to assess the 9 prevalence studies.
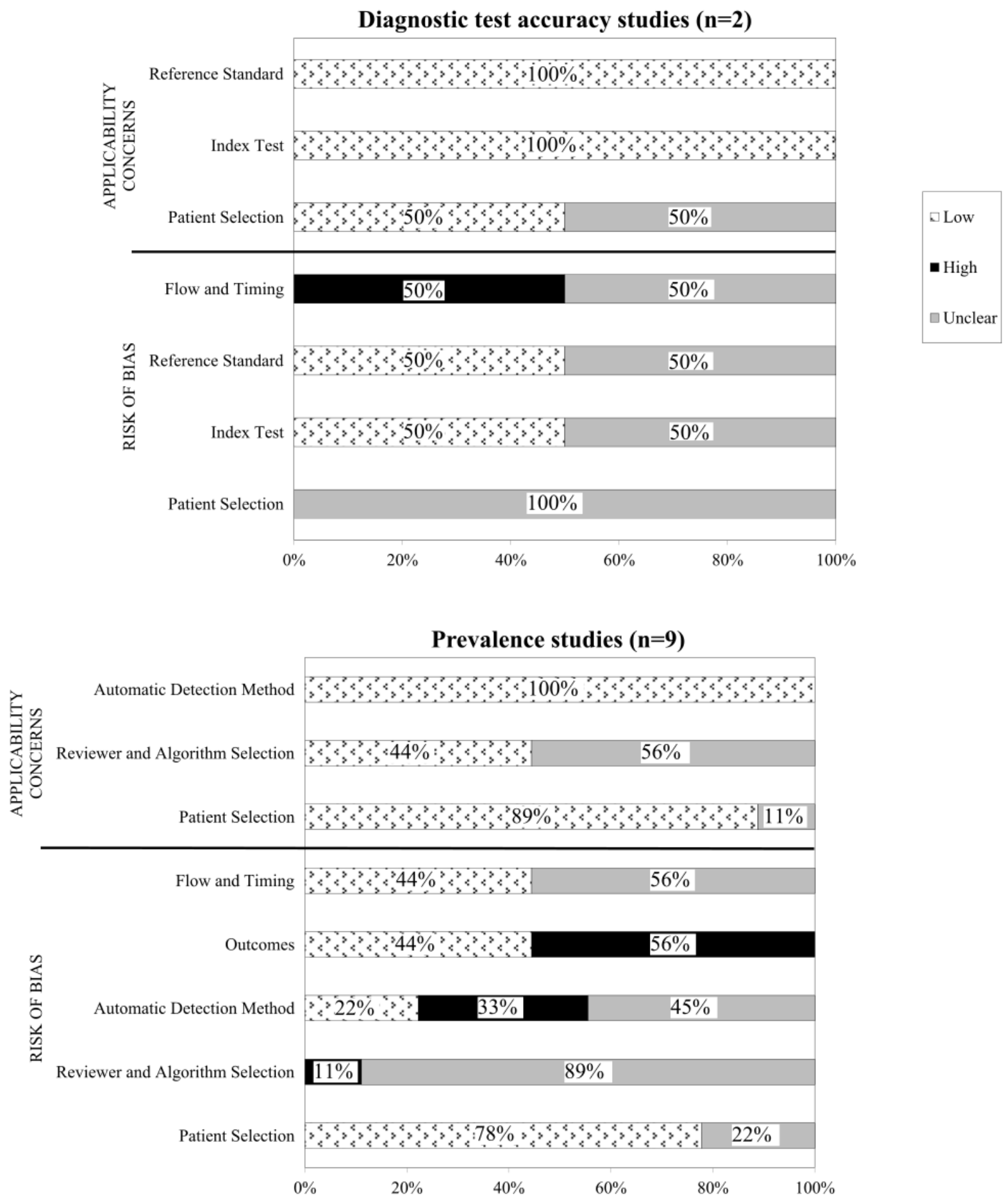
Table 4. The table displays the estimates of diagnostic test accuracy in 2 studies comparing automated trigger-based tools with a manual trigger-based tool as reference standard.

\begin{tabular}{|c|c|c|c|c|c|}
\hline Study & Type of adverse events & $\begin{array}{l}2 \times 2 \text { table for adverse } \\
\text { events (True positive } \\
\text { / false positive / } \\
\text { false negative / true } \\
\text { negative) }\end{array}$ & $\begin{array}{l}\text { Prevalence }^{\mathrm{a}}, \% \\
(95 \% \mathrm{CI})\end{array}$ & $\begin{array}{l}\text { Positive predictive } \\
\text { value }^{\mathrm{b}}, \%(95 \% \mathrm{CI})\end{array}$ & $\begin{array}{l}\text { False negative } \\
\operatorname{rate}^{\mathrm{c}}(\%)\end{array}$ \\
\hline Gerdes and Hardahl, 2013 [44] & Pressure ulcer & $28 / 22 / 12 / 436$ & $5.6(3.6-7.6)$ & $56(42.2-69.8)$ & 30 \\
\hline \multirow[t]{10}{*}{ O’Leary et al, 2013 [41] } & Adverse drug event & $24 / 22 / 20 / \mathrm{N} / \mathrm{A}^{\mathrm{d}}$ & $9.6(5.9-13.3)$ & $52.2(37.7-66.6)$ & 45.5 \\
\hline & Hospital acquired infection & $7 / 11 / 4 /$ N/A & $2.8(0.8-4.9)$ & $38.9(16.4-61.4)$ & 36.4 \\
\hline & Operative or procedural injury & $5 / 4 / 4 /$ N/A & $2(0.3-3.7)$ & $55.6(23.1-88)$ & 44.4 \\
\hline & $\begin{array}{l}\text { Manifestation of poor glycemic } \\
\text { control }\end{array}$ & $3 / 2 / 5 / N / A$ & $1.2(-0.2$ to 2.6$)$ & $60(17.1-102.9)$ & 62.5 \\
\hline & Pressure ulcer & $0 / 8 / 2 / \mathrm{N} / \mathrm{A}$ & $0(0-0)$ & $0(0-0)$ & 100 \\
\hline & Venous thromboembolism & $5 / 1 / 0 / \mathrm{N} / \mathrm{A}$ & $2(0.3-3.7)$ & $83.3(53.5-113.2)$ & 0 \\
\hline & Acute renal failure & $2 / 1 / 0 / \mathrm{N} / \mathrm{A}$ & $0.8(-0.3$ to 1.9$)$ & $66.7(13.3-120)$ & 0 \\
\hline & Delirium & $0 / 0 / 0 / \mathrm{N} / \mathrm{A}$ & $0(0-0)$ & $0(0-0)$ & 0 \\
\hline & Fall & $0 / 0 / 0 / \mathrm{N} / \mathrm{A}$ & $0(0-0)$ & $0(0-0)$ & 0 \\
\hline & Other & $0 / 2 / 5 / \mathrm{N} / \mathrm{A}$ & $0(0-0)$ & $0(0-0)$ & 100 \\
\hline
\end{tabular}

${ }^{\mathrm{a}}$ Prevalence is calculated by true positive/total number of patients.

${ }^{\mathrm{b}}$ Calculated as triggers corresponding to an adverse event out of all triggers=true positive/(true positive+false positive).

${ }^{\mathrm{c}}$ Calculated as false negative/(false negative+true positive).

${ }^{\mathrm{d}} \mathrm{N} / \mathrm{A}$ : not applicable.

Across all the 11 studies, AE prevalence ranged from $0 \%$ to $17.9 \%$, with a median of $0.8 \%$. The PPV of all triggers to detect AEs ranged from $0 \%$ to $100 \%$ across studies, with a median of $40 \%$. Some triggers are used in different studies and have different PPV values: (1) in 6 studies, hypoglycemia [25,37-41] had a PPV ranging from $15.8 \%$ to $60 \%$; (2) in 5 studies, naloxone [25,36,41,42,45] had a PPV ranging from $20 \%$ to 91\%; (3) in 4 studies, flumazenil [25,36,41,42] had a PPV ranging from $38.9 \%$ to $83.3 \%$; and (4) in 4 studies, protamine $[25,36,42,43]$ had a PPV ranging from $0 \%$ to $60 \%$. We were unable to determine the AE prevalence, PPV, preventability, and severity in $40.4 \%, 10.5 \%, 71.1 \%$, and $68.4 \%$ of the studies, respectively. These studies did not report the overall number of records analyzed, triggers, or AEs; or the studies did not conducted the analysis concerned. Detailed results for each trigger with prevalence, preventability, severity, and PPV are presented in Figures 3 and 4. Only 1 study supplied information on interrater reliability, reporting a kappa value of .52 to .78 [41].

\section{Challenges and Author Proposed Solutions}

The challenges reported by authors concerned the relative large number of false alarms, the dependence of PPV on AE prevalence, and incomplete patient records leading to missed events. To reduce the fraction of false alarms, several authors suggested to use a threshold value for the triggers used based on patient characteristics $[36,38,40,43]$. For example, specific disease states of patients must have triggers with different threshold as the consequences might be stronger because of their disease. Authors from one study suggested to measure sensitivity and specificity instead of PPV, as latter is known to be largely affected by AE prevalence [38]. Another author group suggested to either improve completeness of patient information documentation or to combine different data sources to increase the chance to detect AEs as each data source contains different information type [42]. 
Figure 3. Prevalence, preventability, severity, and positive predictive value (PPV) for all the 11 studies. The figure begins with the results of all the triggers or adverse events (AEs) combined, then for each group of trigger order from the most studied to the least studied (part 1). Severity levels based on the National Coordinating Council for Medication Error Reporting and Prevention: $\mathrm{D}=$ an error that reached the patient and required monitoring or intervention to confirm that it resulted in no harm to the patient; $\mathrm{E}=$ temporary harm to the patient and required intervention; $\mathrm{F}=$ temporary harm to the patient and required initial or prolonged hospitalization; $\mathrm{G}=$ permanent patient harm; $\mathrm{H}=$ intervention required to sustain life; and $\mathrm{I}=$ patient death. $\mathrm{H} 1$ : hospital 1; H2: hospital 2. 


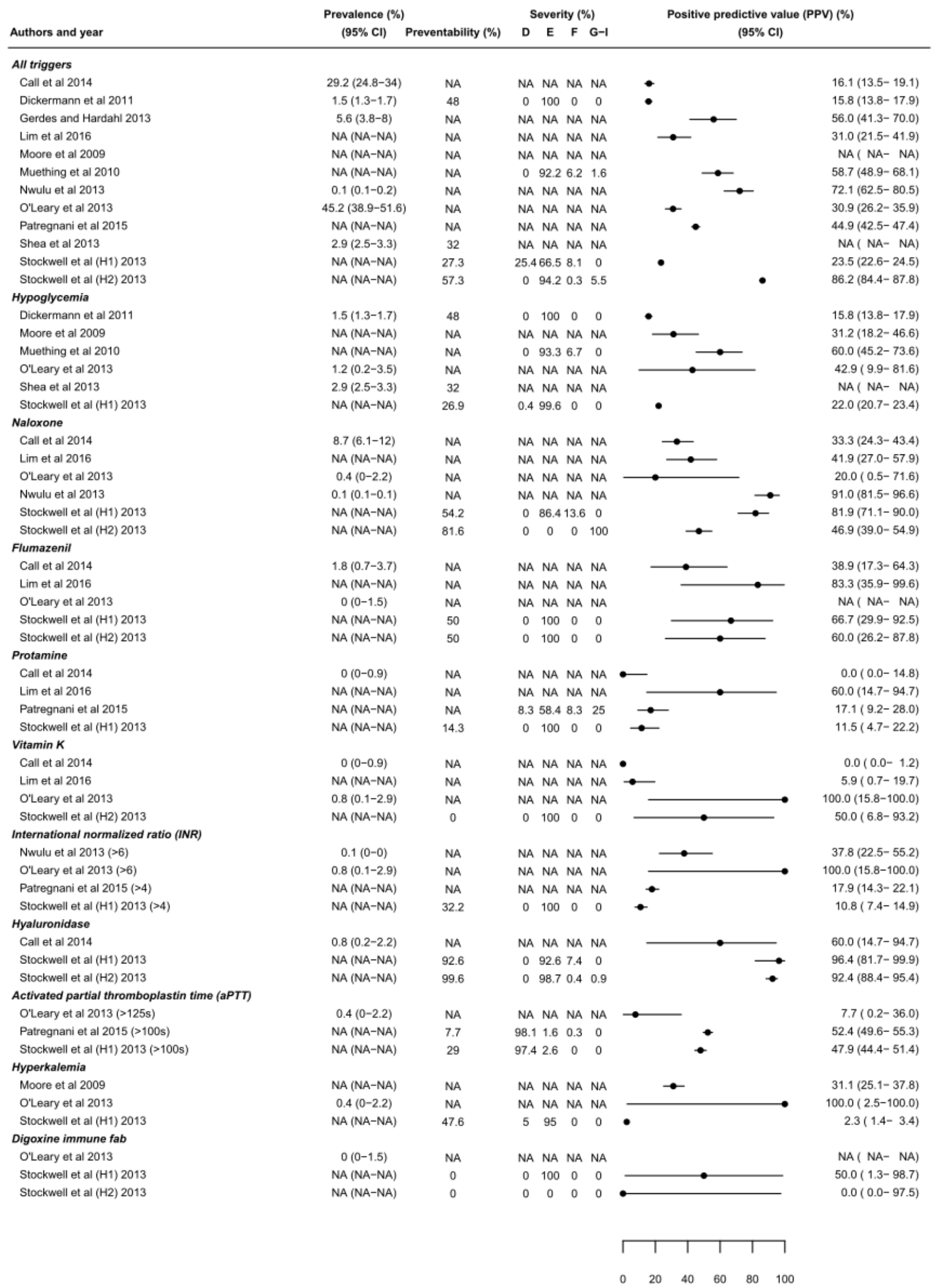


Figure 4. Prevalence, preventability, severity, and positive predictive value (PPV) for all the 11 studies. The figure begins with the results of all the triggers or adverse events (AEs) combined, then for each group of trigger order from the most studied to the least studied (part 2). Severity levels based on the National Coordinating Council for Medication Error Reporting and Prevention: $\mathrm{D}=$ an error that reached the patient and required monitoring or intervention to confirm that it resulted in no harm to the patient; $\mathrm{E}=$ temporary harm to the patient and required intervention; $\mathrm{F}=$ temporary harm to the patient and required initial or prolonged hospitalization; $\mathrm{G}=$ permanent patient harm; $\mathrm{H}=$ intervention required to sustain life; I=patient death. H1: hospital 1; H2: hospital 2; VT: venous thromboembolism; IR: incident report. 


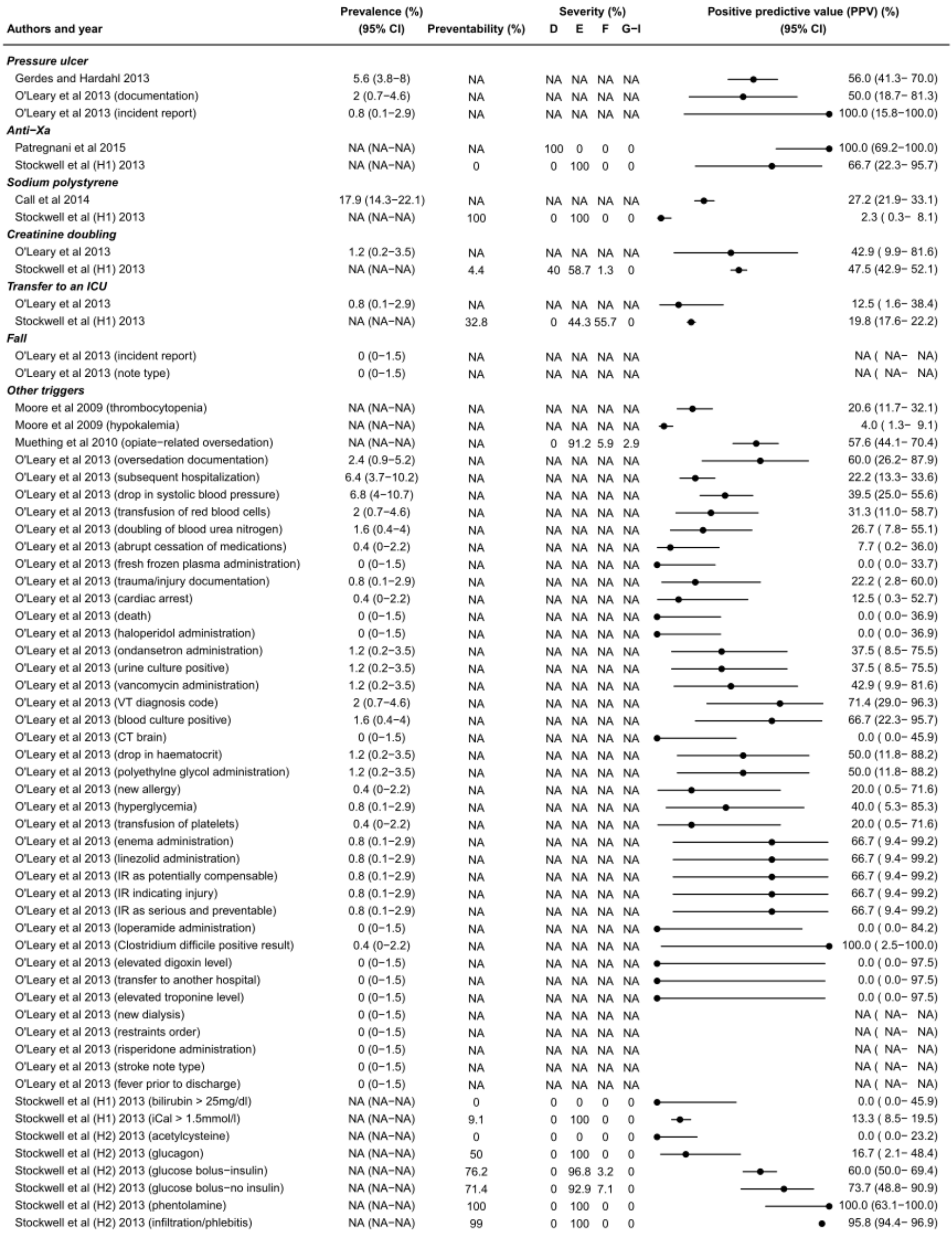




\section{Discussion}

\section{Aim of This Review and Principal Findings}

The goal of this systematic review was to synthesize the evidence concerning the development of a semi or fully automated method of AE detection in EHRs using trigger tools. The results show a broad variation in applied methods, selection of triggers, and estimates of AE prevalence and trigger-based PPVs. Insufficient reporting precluded full appreciation of the risk of bias and concerns regarding applicability.

Our findings are in line with another systematic review focusing on manual GTT [10]. Several interstudy differences can be hypothesized to explain the heterogeneity in the observed study estimates of AE prevalence and PPVs. These include the time frame (range: 1-51 months); the sample size (range: 250-54,244 records); the data sources and EHR system types; the automated approach; the review process; but also the differences in defining AEs, its severity, and preventability.

In addition, the choice and definition of triggers (eg, INR $\geq 6$ $[41,45]$ and INR $>4[25,43])$ affect overall and per-trigger PPV. In some studies, only triggers identifying unique AEs are used for analysis, leading to varying results for similar triggers. Furthermore, the PPV is deemed to be strongly affected by the study's AE prevalence. We could not test for this because of the reviewed studies' heterogeneous definitions of prevalence. These included AEs per 100 patients admitted, AEs per 1000 patient days, or AEs per month. The missing information concerning the total number of patients included $(36.4 \%$ of the 11 studies) hindered computation of prevalence estimates for these studies. The PPV of the triggers ranged from $0 \%$ to $100 \%$. Even for the same trigger, high variability was observed.

Similar parallels can be observed regarding AEs' severity. Even when naloxone was used as a trigger in two hospitals in the same study [25], although one hospital had a severity level of $96.4 \%$, falling into category "temporary harm to the patient and required intervention," the other had a severity level $100 \%$, falling into the categories "permanent patient harm or patient death." Several included studies suggested improvement of PPV values by limiting triggers to specific patient subpopulations, or by modifying thresholds based on age or other patient characteristics [36,40]. Moore et al [38] suggested using sensitivity and specificity instead of PPV, as the former is less affected by changes in AE incidence. The studies did not address difficulties or opportunities regarding the implementation of trigger tool-based methods, but we do not exclude that such information can be found in more qualitative types of research that we did not collect for this review.

The decision of several of the reviewed studies' authors to employ semiautomatic approaches or to focus mainly on ADEs reflects the difficulty of detecting AEs fully automatically. The extracted high proportion of false alarms in various studies is likely explained in part by these difficulties. Although several studies showed that automatic tools can detect up to $69 \%$ of ADEs found manually, automatic detection of AEs overall remains problematic [47-50]. In our review, the sensitivity to detect AEs ranged from $0 \%$ to $100 \%$. General AE detection requires more advanced technology, such as NLP, which can read and process free-text narrative [51,52], addressing complex issues such as negation and lexical variation of terminology. Previous research has suggested that automated AE detection methods were superior to manual tools $[26,53,54]$. Automated AE detection methods have the potential to screen large numbers of patients to save valuable time, which would not be possible by doing manually by human reviewers with the same accuracy. Yet, timely intervention is an important factor to avoid complications and patient harm when an AE is detected. Even if PPVs are not high for all AEs, automated AE detection methods provide an excellent alternative to the manual approach by saving time and resources [14]. As shown by the systematic review of Wang et al, the use of NLP with EHRs is still at its infancy, and closer collaboration of NLP experts and clinicians is missing [46]. Nevertheless, automated AE detection methods are a promising approach for patient safety improvement.

Looking deeper into the individual studies via our quality assessment tools, we realized that, for most, their methodology, their results, or both were reported in ways that were unclear, inconsistent, or incomplete, which challenged our risk of bias and applicability assessments. Several studies failed to report the number of records screened or the type of patients sampled. These elements, however, are crucial for interpretation of the various estimates and also for its reproducibility. In other studies, the number of triggers or AEs remained unclear. AE severity and preventability were not always reported, and the variation in use of definitions for AEs, severity, and preventability further hampered interpretation of estimates across studies. Interestingly, the majority of studies lacked to report PPV CIs, which is essential for the swift interpretation of the estimate's precision.

Although not part of our quality assessment tools, we detected risk of selective outcome reprint in some studies. In these, severity and/or preventability assessments are reported in the Methods sections but not addressed in the Results section. Only one study checked for the presence of triggers at admission [42]. Such triggers or AEs should typically be excluded from the evaluation, as it cannot be targeted with interventions aiming at improving quality of care. Furthermore, although a reviewer's expertise plays an important role in the detection of AEs, information concerning their professional background, experience, or training was mostly absent. Overall, there is substantial room for improvement of the quality of reporting.

\section{Limitations}

Our decision to limit the inclusion criteria to studies concerning semi or fully automated trigger tool-like methodologies disqualified many studies, including those employing recommendations from the Harvard Medical Practice Study [28,55,56], machine learning [57], early warning systems [58-61], or other methods [62,63]. However, it allowed us to show that even within a narrow set of trigger-based tools, methods and outcomes varied considerably. The decision to exclude studies involving outpatients $[62,64,65]$ or mixes of inpatients and outpatients [66] further decreased the number of eligible studies but increased the comparability of the patient population evaluated. Nevertheless, the overall low number of 
eligible studies precluded statistical evaluation of the impact of sources of variation and bias. The evaluation of diagnostic test accuracy is generally hampered by the absence of a widely accepted reference standard.

\section{Conclusions}

This systematic review provides an overview about the application and outcomes of (semi) automatic trigger-based AE detection tools. We observed but could not formally explain the high degree of interstudy variation in reported estimates of prevalence and PPV, even in cases where similar triggers were tested. Although the AHRQ recently released common formats for event reporting [67], which supports the implementation of $\mathrm{AE}$ detection in the $\mathrm{EHR}$, standards for the reporting of $\mathrm{AE}$ detection studies using trigger tools are lacking, yet urgently needed to overcome the methodological heterogeneity in future studies. We need better standards for reporting in this field of research to increase reproducibility, interpretation, and avoidance of research waste. A more standardized use of definitions of the types, severity, and preventability of AEs is desirable. We therefore call for a set of recommendations for the conduct and reporting of future studies and in the meantime, suggest authors, peer reviewers, and editors to pay special attention to complete reporting of study population, AE and trigger definitions, experience, training, and background of reviewers; methods employed to check for triggers and/or AEs at patient admission; and complete reporting of outcome data (numbers of triggers, nominators and denominators of the prevalence, and PPV).

\section{Acknowledgments}

The authors would like to thank Barbara Schärer for her assistance in data extraction and quality assessment as part of her Master studies.

\section{Authors' Contributions}

MS developed the idea for the study. MS, SNM, and AWSR contributed to the concept, design, analysis, and interpretation of data. SNM contributed to the drafting of the manuscript. AWSR contributed to the analysis and interpretation of the data. DA, RS, HUR, MMJ, and AWSR contributed to the screening and extraction phases, the interpretation of data, and the critical revision of the manuscript. All authors approved the final version.

\section{Conflicts of Interest}

None declared.

\section{Multimedia Appendix 1}

Hausner et al's approach.

[PDF File (Adobe PDF File), 16KB-Multimedia Appendix 1]

\section{Multimedia Appendix 2}

Quality Assessment tool for Diagnostic Accuracy Studies-2 (QUADAS-2) instrument.

[PDF File (Adobe PDF File), 42KB-Multimedia Appendix 2]

\section{Multimedia Appendix 3}

Trigger tool Quality Assessment Tool.

[PDF File (Adobe PDF File), 42KB-Multimedia Appendix 3]

\section{References}

1. Woloshynowych M, Neale G, Vincent C. Case record review of adverse events: a new approach. Qual Saf Health Care 2003 Dec;12(6):411-415 [FREE Full text] [Medline: 14645755]

2. Vincent C, Neale G, Woloshynowych M. Adverse events in British hospitals: preliminary retrospective record review. Br Med J 2001 Mar 3;322(7285):517-519 [FREE Full text] [Medline: 11230064]

3. Institute of Medicine. In: Kohn LT, Corrigan JM, Donaldson MS, editors. To Err is Human: Building a Safer Health System. Washington, DC: The National Academies Press; 2000.

4. Classen D. Medication safety: moving from illusion to reality. J Am Med Assoc 2003 Mar 05;289(9):1154-1156. [Medline: 12622587]

5. Adler L, Yi D, Li M, McBroom B, Hauck L, Sammer C, et al. Impact of Inpatient Harms on Hospital Finances and Patient Clinical Outcomes. J Patient Saf 2015 Mar 23:- (Forthcoming)(forthcoming). [doi: 10.1097/PTS.0000000000000171] [Medline: 25803176] 
6. Baker GR, Norton PG, Flintoft V, Blais R, Brown A, Cox J, et al. The Canadian Adverse Events Study: the incidence of adverse events among hospital patients in Canada. CMAJ 2004 May 25;170(11):1678-1686 [FREE Full text] [Medline: $\underline{15159366]}$

7. Brennan TA, Leape LL, Laird NM, Hebert L, Localio AR, Lawthers AG, Harvard Medical Practice Study I. Incidence of adverse events and negligence in hospitalized patients: results of the Harvard Medical Practice Study I. 1991. Qual Saf Health Care 2004 Apr;13(2):145-51; discussion 151 [FREE Full text] [Medline: 15069223]

8. Leape LL, Brennan TA, Laird N, Lawthers AG, Localio AR, Barnes BA, et al. The nature of adverse events in hospitalized patients. Results of the Harvard Medical Practice Study II. N Engl J Med 1991 Feb 7;324(6):377-384. [doi: 10.1056/NEJM199102073240605] [Medline: 1824793]

9. Thomas EJ, Studdert DM, Burstin HR, Orav EJ, Zeena T, Williams EJ, et al. Incidence and types of adverse events and negligent care in Utah and Colorado. Med Care 2000 Mar;38(3):261-271. [Medline: 10718351]

10. Hibbert PD, Molloy CJ, Hooper TD, Wiles LK, Runciman WB, Lachman P, et al. The application of the Global Trigger Tool: a systematic review. Int J Qual Health Care 2016 Dec 01;28(6):640-649. [doi: 10.1093/intqhc/mzw115] [Medline: 27664822]

11. Rosen AK, Mull HJ. Identifying adverse events after outpatient surgery: improving measurement of patient safety. BMJ Qual Saf 2016 Jan;25(1):3-5. [doi: 10.1136/bmjqs-2015-004752] [Medline: 26453634]

12. Gandhi TK, Seger DL, Bates DW. Identifying drug safety issues: from research to practice. Int J Qual Health Care 2000 Feb;12(1):69-76. [Medline: 10733086]

13. Classen DC, Resar R, Griffin F, Federico F, Frankel T, Kimmel N, et al. 'Global trigger tool' shows that adverse events in hospitals may be ten times greater than previously measured. Health Aff (Millwood) 2011 Apr;30(4):581-589 [FREE Full text] [doi: 10.1377/hlthaff.2011.0190] [Medline: 21471476]

14. Murff HJ, Patel VL, Hripcsak G, Bates DW. Detecting adverse events for patient safety research: a review of current methodologies. J Biomed Inform 2003;36(1-2):131-143 [FREE Full text] [Medline: 14552854]

15. Ausserhofer D, Zander B, Busse R, Schubert M, De Geest S, Rafferty AM, RN4CAST consortium. Prevalence, patterns and predictors of nursing care left undone in European hospitals: results from the multicountry cross-sectional RN4CAST study. BMJ Qual Saf 2014 Feb;23(2):126-135. [doi: 10.1136/bmjqs-2013-002318] [Medline: 24214796]

16. Berry LL, Segal R, Sherrin TP, Fudge KA. Sensitivity and specificity of three methods of detecting adverse drug reactions. Am J Hosp Pharm 1988 Jul;45(7):1534-1539. [Medline: 3046347]

17. Rogers AS, Israel E, Smith CR, Levine D, McBean AM, Valente C, et al. Physician knowledge, attitudes, and behavior related to reporting adverse drug events. Arch Intern Med 1988 Jul;148(7):1596-1600. [Medline: 3382304]

18. Rozich JD, Haraden CR, Resar RK. Adverse drug event trigger tool: a practical methodology for measuring medication related harm. Qual Saf Health Care 2003 Jun;12(3):194-200 [FREE Full text] [Medline: 12792009]

19. Resar RK, Rozich JD, Simmonds T, Haraden CR. A trigger tool to identify adverse events in the intensive care unit. Jt Comm J Qual Patient Saf 2006 Oct;32(10):585-590. [Medline: 17066996]

20. Cullen DJ, Bates DW, Small SD, Cooper JB, Nemeskal AR, Leape LL. The incident reporting system does not detect adverse drug events: a problem for quality improvement. Jt Comm J Qual Improv 1995 Oct;21(10):541-548. [Medline: $\underline{8556111]}$

21. West AN, Weeks WB, Bagian JP. Rare adverse medical events in VA inpatient care: reliability limits to using patient safety indicators as performance measures. Health Serv Res 2008 Feb;43(1 Pt 1):249-266 [FREE Full text] [doi: 10.1111/j.1475-6773.2007.00760.x] [Medline: 18211528]

22. Griffin FA, Resar RK. IHI. 2009. IHI Global Trigger Tool for Measuring Adverse Events URL: http://www.ihi.org/resources/ Pages/Tools/IHIGlobalTriggerToolforMeasuringAEs.aspx [accessed 2018-05-04] [WebCite Cache ID 6z9v8yzwv]

23. Adler L, Denham CR, McKeever M, Purinton R, Guilloteau F, Moorhead JD, et al. Global trigger tool: implementation basics. J Patient Saf 2008;4(4):245-249. [doi: 10.1097/pts.0b013e31818e8a87]

24. Doupi P. Using EHR data for monitoring and promoting patient safety: reviewing the evidence on trigger tools. Stud Health Technol Inform 2012;180:786-790. [Medline: 22874299]

25. Stockwell DC, Kirkendall E, Muething SE, Kloppenborg E, Vinodrao H, Jacobs BR. Automated adverse event detection collaborative: electronic adverse event identification, classification, and corrective actions across academic pediatric institutions. J Patient Saf 2013 Dec;9(4):203-210. [doi: 10.1097/PTS.0000000000000055] [Medline: 24257063]

26. Li Q, Melton K, Lingren T, Kirkendall ES, Hall E, Zhai H, et al. Phenotyping for patient safety: algorithm development for electronic health record based automated adverse event and medical error detection in neonatal intensive care. $\mathrm{J}$ Am Med Inform Assoc 2014;21(5):776-784 [FREE Full text] [doi: 10.1136/amiajnl-2013-001914] [Medline: 24401171]

27. Menendez ME, Janssen SJ, Ring D. Electronic health record-based triggers to detect adverse events after outpatient orthopaedic surgery. BMJ Qual Saf 2016 Jan;25(1):25-30. [doi: 10.1136/bmjqs-2015-004332] [Medline: 26359272]

28. Murff HJ, Forster AJ, Peterson JF, Fiskio JM, Heiman HL, Bates DW. Electronically screening discharge summaries for adverse medical events. J Am Med Inform Assoc 2003;10(4):339-350 [FREE Full text] [doi: 10.1197/jamia.M1201] [Medline: 12668691] 
29. Govindan M, Van Citters AD, Nelson EC, Kelly-Cummings J, Suresh G. Automated detection of harm in healthcare with information technology: a systematic review. Qual Saf Health Care 2010 Oct;19(5):e11. [doi: 10.1136/qshc.2009.033027] [Medline: 20671081]

30. Reitsma JB, Rutjes AW, Whiting P, Vlassov VV, Leeflang MMG, Deeks JJ. Chapter 9: Assessing methodological quality. In: Cochrane Handbook for Systematic Reviews of Diagnostic Test Accuracy. London, England: The Cochrane Collaboration; 2009.

31. Higgins JP, Green S, editors. Cochrane Handbook for Systematic Reviews of Interventions. West Sussex, England: John Wiley \& Sons Ltd; 2011.

32. Moher D, Liberati A, Tetzlaff J, Altman DG. Preferred reporting items for systematic reviews and meta-analyses: the PRISMA statement. PLoS Med 2009 Jul 21;6(7):e1000097 [FREE Full text] [doi: 10.1371/journal.pmed.1000097] [Medline: 19621072]

33. Hausner E, Waffenschmidt S, Kaiser T, Simon M. Routine development of objectively derived search strategies. Syst Rev 2012 Feb 29;1:19 [FREE Full text] [doi: 10.1186/2046-4053-1-19] [Medline: 22587829]

34. Hausner E, Guddat C, Hermanns T, Lampert U, Waffenschmidt S. Development of search strategies for systematic reviews: validation showed the noninferiority of the objective approach. J Clin Epidemiol 2015 Feb;68(2):191-199 [FREE Full text] [doi: 10.1016/j.jclinepi.2014.09.016] [Medline: 25464826]

35. Whiting PF, Rutjes AW, Westwood ME, Mallett S, Deeks JJ, Reitsma JB, et al. QUADAS-2: a revised tool for the quality assessment of diagnostic accuracy studies. Ann Intern Med 2011 Oct 18;155(8):529-536. [doi: 10.7326/0003-4819-155-8-201110180-00009] [Medline: 22007046]

36. Call RJ, Burlison JD, Robertson JJ, Scott JR, Baker DK, Rossi MG, et al. Adverse drug event detection in pediatric oncology and hematology patients: using medication triggers to identify patient harm in a specialized pediatric patient population. $\mathbf{J}$ Pediatr 2014 Sep;165(3):447-52.e4 [FREE Full text] [doi: 10.1016/j.jpeds.2014.03.033] [Medline: 24768254]

37. Dickerman MJ, Jacobs BR, Vinodrao H, Stockwell DC. Recognizing hypoglycemia in children through automated adverse-event detection. Pediatrics 2011 Apr;127(4):e1035-e1041. [doi: 10.1542/peds.2009-3432] [Medline: 21402631]

38. Moore C, Li J, Hung C, Downs J, Nebeker JR. Predictive value of alert triggers for identification of developing adverse drug events. J Patient Saf 2009 Dec;5(4):223-228. [doi: 10.1097/PTS.0b013e3181bc05e5] [Medline: 22130215]

39. Muething SE, Conway PH, Kloppenborg E, Lesko A, Schoettker PJ, Seid M, et al. Identifying causes of adverse events detected by an automated trigger tool through in-depth analysis. Qual Saf Health Care 2010 Oct;19(5):435-439. [doi: 10.1136/qshc.2008.031393] [Medline: 20798069]

40. Shea PL, Spaeder MC, Sayal P, Jacobs BR, Stockwell DC. Hypoglycemia adverse events in PICUs and cardiac ICUs: differentiating preventable and nonpreventable events*. Pediatr Crit Care Med 2013 Oct;14(8):741-746. [doi: 10.1097/PCC.0b013e3182975f0f] [Medline: 23863820]

41. O'Leary KJ, Devisetty VK, Patel AR, Malkenson D, Sama P, Thompson WK, et al. Comparison of traditional trigger tool to data warehouse based screening for identifying hospital adverse events. BMJ Qual Saf 2013 Feb;22(2):130-138. [doi: 10.1136/bmjqs-2012-001102] [Medline: 23038408]

42. Lim D, Melucci J, Rizer MK, Prier BE, Weber RJ. Detection of adverse drug events using an electronic trigger tool. Am J Health Syst Pharm 2016 Sep 01;73(17 Suppl 4):S112-S120. [doi: 10.2146/ajhp150481] [Medline: 27543596]

43. Patregnani JT, Spaeder MC, Lemon V, Diab Y, Klugman D, Stockwell DC. Monitoring the harm associated with use of anticoagulants in pediatric populations through trigger-based automated adverse-event detection. Jt Comm J Qual Patient Saf 2015 Mar;41(3):108-114. [Medline: 25977126]

44. Gerdes LU, Hardahl C. Text mining electronic health records to identify hospital adverse events. Stud Health Technol Inform 2013;192:1145. [Medline: 23920919]

45. Nwulu U, Nirantharakumar K, Odesanya R, McDowell SE, Coleman JJ. Improvement in the detection of adverse drug events by the use of electronic health and prescription records: an evaluation of two trigger tools. Eur J Clin Pharmacol 2013 Feb;69(2):255-259. [doi: 10.1007/s00228-012-1327-1] [Medline: 22706621]

46. Wang Y, Wang L, Rastegar-Mojarad M, Moon S, Shen F, Afzal N, et al. Clinical information extraction applications: a literature review. J Biomed Inform 2018 Jan;77:34-49 [FREE Full text] [doi: 10.1016/j.jbi.2017.11.011] [Medline: 29162496]

47. Jha AK, Kuperman GJ, Teich JM, Leape L, Shea B, Rittenberg E, et al. Identifying adverse drug events: development of a computer-based monitor and comparison with chart review and stimulated voluntary report. J Am Med Inform Assoc 1998;5(3):305-314 [FREE Full text] [Medline: $\underline{\text { 9609500] }}$

48. Bates DW, Leape LL, Cullen DJ, Laird N, Petersen LA, Teich JM, et al. Effect of computerized physician order entry and a team intervention on prevention of serious medication errors. J Am Med Assoc 1998 Oct 21;280(15):1311-1316. [Medline: 9794308]

49. Classen DC, Pestotnik SL, Evans RS, Burke JP. Computerized surveillance of adverse drug events in hospital patients. J Am Med Assoc 1991 Nov 27;266(20):2847-2851. [Medline: 1942452]

50. Raschke RA, Gollihare B, Wunderlich TA, Guidry JR, Leibowitz AI, Peirce JC, et al. A computer alert system to prevent injury from adverse drug events: development and evaluation in a community teaching hospital. J Am Med Assoc 1998 Oct 21;280(15):1317-1320. [Medline: 9794309] 
51. Hripcsak G, Friedman C, Alderson PO, DuMouchel W, Johnson SB, Clayton PD. Unlocking clinical data from narrative reports: a study of natural language processing. Ann Intern Med 1995 May 01;122(9):681-688. [Medline: 7702231]

52. Friedman C. Towards a comprehensive medical language processing system: methods and issues. Proc AMIA Annu Fall Symp 1997:595-599 [FREE Full text] [Medline: 9357695]

53. Murff HJ, FitzHenry F, Matheny ME, Gentry N, Kotter KL, Crimin K, et al. Automated identification of postoperative complications within an electronic medical record using natural language processing. J Am Med Assoc 2011 Aug 24;306(8):848-855. [doi: 10.1001/jama.2011.1204] [Medline: 21862746]

54. Melton GB, Hripcsak G. Automated detection of adverse events using natural language processing of discharge summaries. J Am Med Inform Assoc 2005;12(4):448-457 [FREE Full text] [doi: 10.1197/jamia.M1794] [Medline: 15802475]

55. Szekendi MK, Sullivan C, Bobb A, Feinglass J, Rooney D, Barnard C, et al. Active surveillance using electronic triggers to detect adverse events in hospitalized patients. Qual Saf Health Care 2006 Jun;15(3):184-190 [FREE Full text] [doi: 10.1136/qshc.2005.014589] [Medline: 16751468]

56. Kane-Gill SL, MacLasco AM, Saul MI, Politz ST, Kloet MA, Kim C, et al. Use of text searching for trigger words in medical records to identify adverse drug reactions within an intensive care unit discharge summary. Appl Clin Inform 2016 Jul 13;7(3):660-671 [FREE Full text] [doi: 10.4338/ACI-2016-03-RA-0031] [Medline: 27453336]

57. Marella WM, Sparnon E, Finley E. Screening electronic health record-related patient safety reports using machine learning. J Patient Saf 2017 Mar;13(1):31-36. [doi: 10.1097/PTS.0000000000000104] [Medline: 24721977]

58. Kavanaugh MJ, So JD, Park PJ, Davis KL. Validation of the intensive care unit early warning dashboard: quality improvement utilizing a retrospective case-control evaluation. Telemed J E Health 2017 Feb;23(2):88-95. [doi: 10.1089/tmj.2016.0073] [Medline: 27391204]

59. Le Lagadec MD, Dwyer T. Scoping review: the use of early warning systems for the identification of in-hospital patients at risk of deterioration. Aust Crit Care 2017 Jul;30(4):211-218. [doi: 10.1016/j.aucc.2016.10.003] [Medline: 27863876]

60. Paliwoda M, New K, Bogossian F. Neonatal Early Warning Tools for recognising and responding to clinical deterioration in neonates cared for in the maternity setting: a retrospective case-control study. Int J Nurs Stud 2016 Sep;61:125-135. [doi: 10.1016/j.ijnurstu.2016.06.006] [Medline: 27348358]

61. Sefton G, Lane S, Killen R, Black S, Lyon M, Sproule C, et al. Accuracy and efficiency of recording paediatric early warning scores (PEWS) using electronic hand-held devices compared with traditional paper-based documentation. Comput Inform Nurs 2017 May;35(5):228-236 [FREE Full text] [doi: 10.1097/CIN.0000000000000305]

62. Long AL, Horvath MM, Cozart H, Eckstrand J, Whitehurst J, Ferranti J. Tailoring adverse drug event surveillance to the paediatric inpatient. Qual Saf Health Care 2010 Oct;19(5):e40 [FREE Full text] [doi: 10.1136/qshc.2009.032680] [Medline: 20511599]

63. Haffner S, von LN, Wirth S, Thürmann PA. Detecting adverse drug reactions on paediatric wards: intensified surveillance versus computerised screening of laboratory values. Drug Saf 2005;28(5):453-464. [Medline: 15853446]

64. Mull HJ, Rosen AK, Shimada SL, Rivard PE, Nordberg B, Long B, et al. Assessing the potential adoption and usefulness of concurrent, action-oriented, electronic adverse drug event triggers designed for the outpatient setting. EGEMS (Wash DC) 2015;3(1):1116 [FREE Full text] [doi: 10.13063/2327-9214.1116] [Medline: 25992386]

65. Rosen AK, Mull HJ, Kaafarani H, Nebeker J, Shimada S, Helwig A, et al. Applying trigger tools to detect adverse events associated with outpatient surgery. J Patient Saf 2011 Mar;7(1):45-59. [doi: 10.1097/PTS.0b013e31820d164b] [Medline: 21921867]

66. Lemon V, Stockwell DC. Automated detection of adverse events in children. Pediatr Clin North Am 2012 Dec;59(6):1269-1278. [doi: 10.1016/j.pcl.2012.08.007] [Medline: 23116524]

67. Patient Safety Organization Privacy Protection. Common Formats for Event Reporting - Hospital Version 2 URL: https:/ /www.psoppc.org/psoppc_web/publicpages/commonFormatsHV2.0 [accessed 2018-03-28] [WebCite Cache ID 6yFTMJEMN]

\section{Abbreviations}

ADE: adverse drug event

AE: adverse event

AHRQ: Agency for Healthcare Research and Quality

DTA: diagnostic test accuracy

EHR: electronic health record

GTT: Global Trigger Tool

HCP: heath care provider

IHI: Institute for Healthcare Improvement

MeSH: medical subject headings

NCC MERP: National Coordinating Council for Medication Error Reporting and Prevention

NLP: natural language processing

PPV: positive predictive value

PSI: Patient Safety Indicator 
QUADAS-2: Quality Assessment tool for Diagnostic Accuracy Studies-2

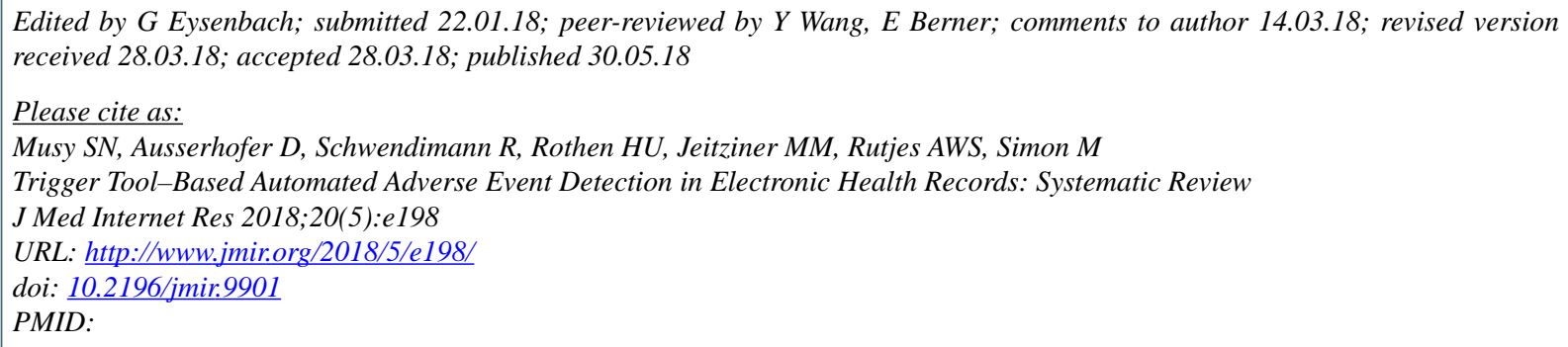

(C) Sarah N Musy, Dietmar Ausserhofer, René Schwendimann, Hans Ulrich Rothen, Marie-Madlen Jeitziner, Anne WS Rutjes, Michael Simon. Originally published in the Journal of Medical Internet Research (http://www.jmir.org), 30.05.2018. This is an open-access article distributed under the terms of the Creative Commons Attribution License (https://creativecommons.org/licenses/by/4.0/), which permits unrestricted use, distribution, and reproduction in any medium, provided the original work, first published in the Journal of Medical Internet Research, is properly cited. The complete bibliographic information, a link to the original publication on http://www.jmir.org/, as well as this copyright and license information must be included. 